\title{
iPermanency: uma ferramenta para gestão da evasão na EaD baseada em Mineração de Dados Educacionais
}

\author{
Jáder Adiél Schmitt, PPGTER/UFSM, jaderadiel@hotmail.com \\ Giliane Bernardi, PPGTER/UFSM, bgiliane@gmail.com \\ Gustavo Zanini Kantorski, UFSM, gustavo.zanini.kantorski@gmail.com
}

\begin{abstract}
Resumo. A evasão na Educação à Distância é um dos temas mais relevantes para a gestão acadêmica nesta modalidade educacional. Em consequência, diversas abordagens tecnológicas que aplicam Mineração de Dados Educacionais para previsão da evasão vêm sendo desenvolvidas. No entanto, a maioria delas não disponibiliza os conhecimentos obtidos para os gestores interessados. Desse modo, este artigo apresenta o desenvolvimento de um aplicativo móvel que dispõe as informações geradas por meio de Mineração de Dados Educacionais, para que estes possam refletir sobre seus resultados. $\mathrm{Na}$ avaliação do aplicativo ficou evidenciado que a disponibilização dessas informações pode ser grande aliada da gestão acadêmica, em busca da mitigação dos números elevados de abandono.
\end{abstract}

Palavras-chave: Educação à Distância, Evasão, Mineração de Dados Educacionais.

\begin{abstract}
The evasion in Distance Education is one of the most relevant topics for academic management in this educational modality. As a consequence, several technological approaches that apply Educational Data Mining to predict evasion have been developed. However, most of them do not provide the knowledge gained to interested managers. In this way, the article presents the development of a mobile application that provides the information of the Educational Data Mining so that they can reflect on their results. In the evaluation of the application it was evidenced that the availability of this information can be great ally of the academic management, in search of the mitigation of the high numbers of abandonment.
\end{abstract}

Keywords: Distance Learning, Evasion, Educational Data Mining.

\section{Introdução}

A Educação à Distância $(\mathrm{EaD})$ está se tornando cada vez mais consolidada no país. Paralelamente, dados do Censo da EaD, realizado pela Associação Brasileira de Educação à Distância (2016), revelam elevados índices de evasão, o que exige da gestão acadêmica maior atenção em relação ao tema. A evasão é definida por Maia e Mattar (2007) como a desistência do aluno em completar o curso, independente da participação ou não nas aulas, ou seja, aquele que desiste do curso em qualquer etapa.

Corroborando a assertiva de Maia e Mattar (2007), a desistência do aluno em completar o curso pode ser constatada nas pesquisas relacionadas ao assunto que estão sendo elaboradas. Algumas, com o viés pedagógico, investigam as causas da evasão [Silveira 2012; Bizarria, Silva e Carneiro 2014; Abbad, Zerbini e Souza 2010; Martins, Gebran e Terçariol 2014]. Outras, com o viés tecnológico, buscam prever os alunos com tendência a evasão aplicando técnicas de Mineração de Dados (MD) [Kantorski et al., 2016; Queiroga et al., 2016; Detoni, Araújo e Cechinel, 2015; Reino et al. 2015; Costa, Cazella e Rigo, 2014; Ferreira e Elia, 2013]. No entanto, boa parte dos trabalhos que aplicam MD se detém nos aspectos técnicos pertinentes à mineração não 
disponibilizando, assim, os seus resultados para que os gestores, com base neles, possam efetuar ações a fim de evitar o processo de evasão.

Por outro lado, o crescente aumento na quantidade de dados gerados diariamente pelos sistemas informacionais, tais como Ambientes Virtuais de Ensino e Aprendizagem (AVEA), traz destaque para área de MD. A MD consiste na exploração de grandes quantidades de dados para detectar padrões que permitem a extração de novos conhecimentos [Silberschatz, Korth e Sundarshan, 2012]. A aplicação da MD para exploração de dados educacionais vem sendo designada como Mineração de Dados Educacionais (MDE) que, segundo Nascimento et al. (2018), possibilita o conhecimento de fatores e indicadores que podem melhorar as propostas educacionais, seja em aspectos pedagógicos ou de gestão.

Geralmente, a gestão de cursos de graduação $\mathrm{EaD}$ em uma instituição pública é composta por poucos gestores, que são responsáveis por um grande número de alunos espalhados em diversos polos de ensino. Nesse cenário, a aplicação de técnicas de MDE para previsão de alunos com tendência à evasão e, consecutivamente, a disponibilização desses dados pode ser um grande aliado do gestor na elaboração de estratégias para evitar a desistência do aluno.

Considerando o contexto, trazido por meio desta seção, este artigo visa apresentar o desenvolvimento de um aplicativo móvel que tem como objetivo disponibilizar dados estratégicos, provenientes de uma MDE, desenvolvida e apresentada em Schmitt (2018), que permitam a realização de ações por parte dos gestores para conter a ocorrência da evasão. Para tal, encontra-se organizado da seguinte forma: na segunda seção são apresentados os trabalhos relacionados a aplicação de MDE para previsão da evasão; a seguir, na terceira seção é exposto o desenvolvimento do aplicativo; na sequência, na seção quatro, a sua avaliação; e, por fim, as conclusões são abordadas na seção cinco.

\section{Trabalhos relacionados}

No trabalho apresentado por Kostopoulos, Sotiris e Panagiotis (2015) foi desenvolvida uma ferramenta, em que um conjunto de dados do aluno era solicitado pelos docentes para que, a partir deles, uma análise fosse realizada com a utilização dos algoritmos de MDE. Após a análise, era disponibilizado um percentual referente à probabilidade de 0 aluno evadir do curso. Os resultados tiveram uma acurácia entre $60 \%$ e $84 \%$ no reconhecimento dos estudantes que possuem um risco elevado de abandonar o curso.

Já no estudo de Rigo e Cazella (2014), em cursos de graduação EaD, foram utilizados dados de interação dos discentes no AVEA. Por meio de uma ferramenta WEB, desenvolvida pelos autores, foi disponibilizada aos docentes a listagem dos alunos com tendência a evadir. Nela, era possível que o professor informasse quais foram as ações pedagógicas realizadas junto a esses alunos a fim de evitar a desistência. Tais dados eram utilizados, posteriormente, por outros docentes, junto a lista de alunos previstos, para que as ações bem-sucedidas em outros casos pudessem ser aplicadas. A ferramenta foi validada em uma turma em que houve uma redução média de $11 \%$ na evasão .

Kantorski et al. (2016) propõem uma abordagem com o objetivo de predizer a evasão em um curso de graduação, na modalidade presencial. Foram utilizados no processo de MDE dados pessoais, acadêmicos e sobre a participação em programas de auxílio estudantil em que foi obtida uma precisão de até 73\% no número de acertos.

A pesquisa de Manhães (2015) propõe arquitetura baseada em MDE para identificar precocemente alunos com risco de evasão em três cursos de graduação 
presenciais. Foram empregados dados do desempenho em duas disciplinas dos cursos em que os resultados obtidos alcançaram uma acurácia média entre $75 \%$ e $80 \%$.

Detoni, Araújo e Cechinel (2015) buscaram detectar os alunos utilizando a contagem de interações no AVEA MOODLE em disciplinas na EaD. O experimento foi realizado em dois cursos. A partir das interações foram aplicados os algoritmos de MDE, onde foram obtidos resultados de até $67 \%$ de acurácia na predição do desempenho do aluno. Uma extensão dessa pesquisa pode ser vista em Queiroga et al. (2016) em que a abordagem foi aplicada na predição de evasão de alunos de dois cursos técnicos a distância. Nesta foram utilizadas somente a contagem de interações de alunos no AVEA. Apenas com esses dados foi obtida uma acurácia de $98,67 \%$.

Burgos et al. (2017) empregaram MDE para detectar o risco da evasão dos alunos. Foram utilizados dados de 104 alunos de cursos de curta duração a distância. Até a quarta semana de curso foi obtido $100 \%$ de acurácia nos acertos. De acordo com os autores, a aplicação da técnica possibilitou a redução aproximada de $14 \%$ na evasão.

A partir dos trabalhos analisados, fica evidenciada uma lacuna na área de predição de evasão. Pelo fato de grande parte das pesquisas se deterem nos aspectos mais técnicos relacionados à $\mathrm{MDE}$, não foram abordadas ferramentas para disponibilização das informações oriundas desse processo de forma a auxiliar os gestores educacionais na tomada de decisões junto aos alunos indicados. Além disso, os trabalhos que disponibilizam alguns de seus resultados, não permitem uma análise dos fatores que tiveram impacto nas respectivas indicações.

\section{A ferramenta: iPermanency}

Para o desenvolvimento da ferramenta foi utilizada a metodologia Mobile- $D$, proposta por Abrahamsson et al. (2004), voltada ao desenvolvimento de aplicativos para dispositivos móveis. As etapas da metodologia são abordadas nas subseções seguintes.

\subsection{Exploração}

A primeira fase consiste na exploração dos requisitos a serem atendidos para o estabelecimento das características básicas do aplicativo. Sendo assim, os requisitos definidos são demonstrados na Tabela 1 .

\section{Tabela 1. Requisitos do aplicativo}

\begin{tabular}{|c|l|}
\hline Código & Descrição \\
\hline R1 & Listar os índices de evasão geral e evasão média anual para cada curso. \\
\hline R2 & Listar os índices de evasão média anual para os polos de ensino de um curso. \\
\hline R3 & Listar os alunos com tendência à evasão de acordo com o polo de ensino. \\
\hline R4 & $\begin{array}{l}\text { Relacionar as informações consideradas na MDE entre os alunos evadidos e } \\
\text { aqueles em que se estima a sua continuidade. }\end{array}$ \\
\hline R5 & $\begin{array}{l}\text { Relacionar as informações consideradas para MDE dos alunos de um polo de } \\
\text { ensino e os concluintes de um curso. }\end{array}$ \\
\hline R6 & Sincronizar as informações da MDE de forma automática. \\
\hline
\end{tabular}

Os requisitos foram estabelecidos buscando facilitar a compreensão dos dados resultantes da MDE pelos gestores. Sendo assim, o primeiro requisito (R1) visa possibilitar uma análise quantitativa em relação à evasão no curso. Já a listagem de índices de evasão média anual por polo de ensino, R2, possibilita uma visão da ocorrência de evasão por polo, permitindo assim, que os gestores direcionem seus esforços no que visa atenuar os índices apresentados. O R3 surge da necessidade de se 
conhecer os alunos com tendência à evasão para que ações possam ser tomadas junto a eles a fim de evitá-las. Já os requisitos R4 e R5 permitem que o gestor visualize os dados analisados pelos algoritmos de MDE que possam estar influenciando na indicação da evasão. Com esses dados, é possível realizar intervenções junto aos docentes/tutores no sentido de incentivar a utilização de determinados recursos do AVEA que, por exemplo, podem não estar sendo utilizados de forma adequada. Por fim, o requisito R6 foi definido para possibilitar a utilização do aplicativo sem a necessidade de possuir conexão com à Internet cada vez que for preciso consultar os dados.

\subsection{Inicialização}

$\mathrm{Na}$ fase de inicialização foram elaborados os artefatos que serviram de base para as demais fases do desenvolvimento. Para facilitar o entendimento, na Figura 1 é apresentada a arquitetura do sistema.

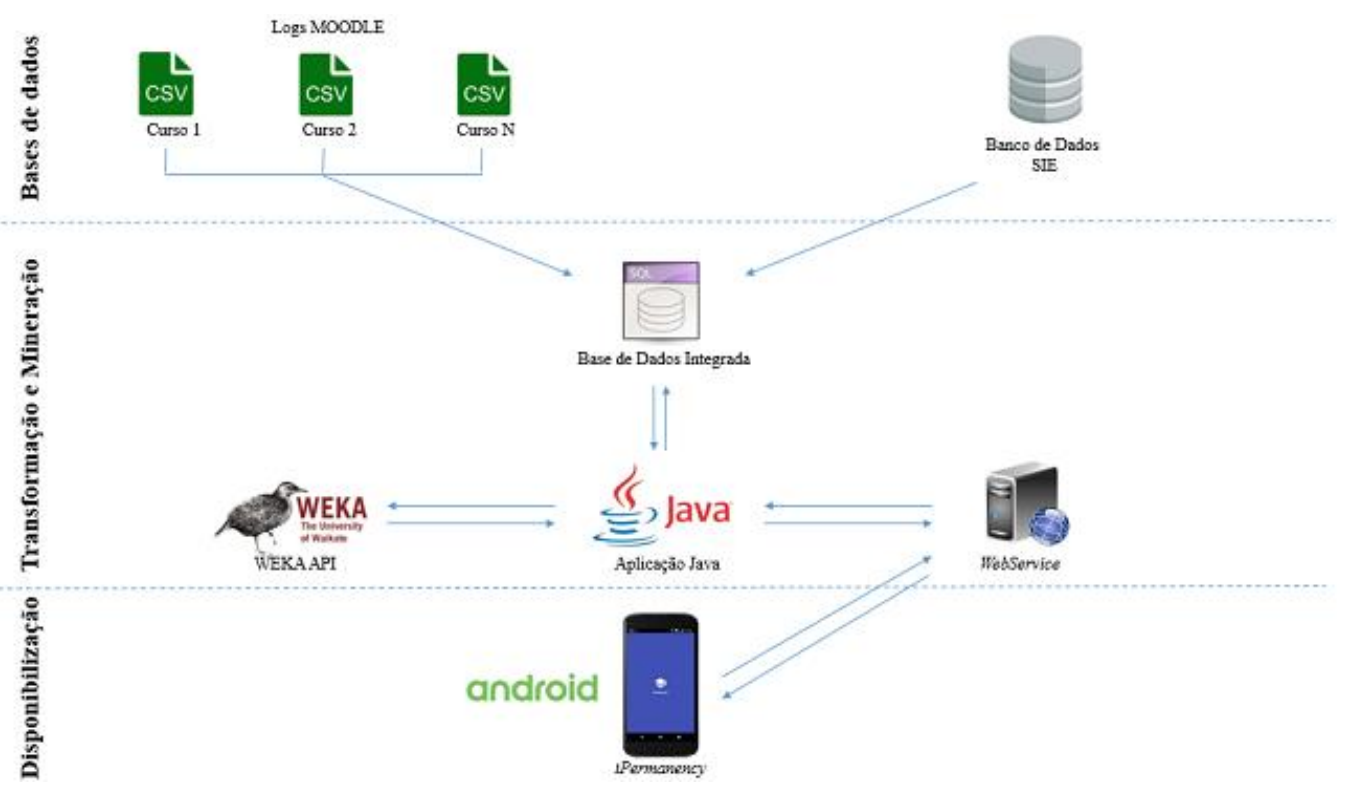

Figura 1. Arquitetura do sistema

A arquitetura do sistema é dividida em três partes. A primeira contém as bases de dados que dispõe das informações que foram utilizadas no processo de MDE. São elas: dados de interação do MOODLE e dados do sistema institucional, o SIE. Na segunda parte consta os componentes que realizam a transformação e MDE, sendo eles: uma base de dados única, contendo tanto os dados do MOODLE quanto os dados do SIE; uma aplicação Java que utiliza a API do WEKA para efetuar o processo de MDE e armazenar os dados resultantes do processo; e, um WebService que disponibiliza os dados resultantes do processamento para serem acessados pelo iPermanency. Por fim, a terceira parte corresponde à disponibilização que contém o aplicativo desenvolvido utilizando a metodologia.

\subsection{Produção e testes}

A produção consiste na fase em que se encontra a maior parte do esforço, a implementação. As funcionalidades do aplicativo podem ser vistas nas Figura 2. 


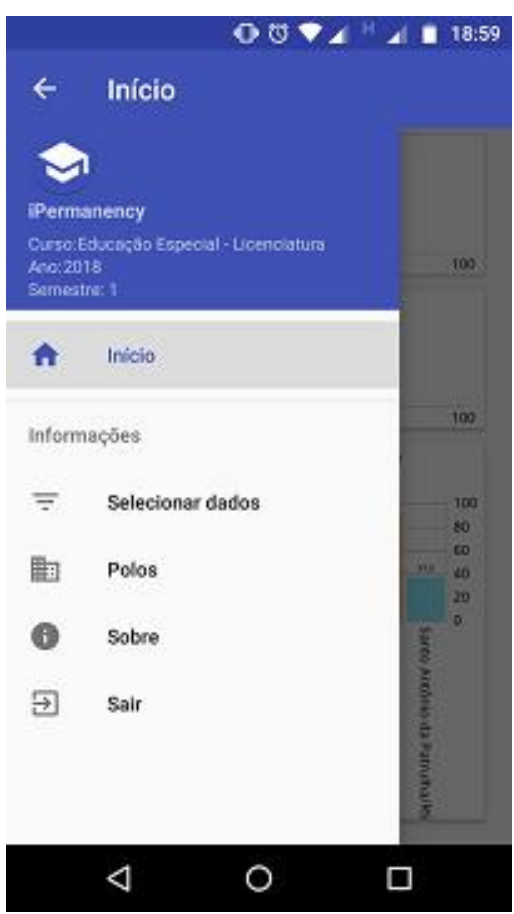

(a)

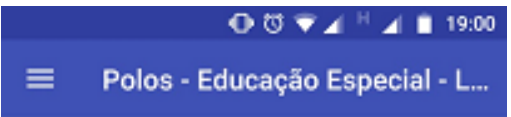

\begin{tabular}{|lc|}
\hline Santa Vitória do Palmar/RS & $\vdots$ \\
\hline Trés Passos/RS & $\vdots$ \\
\hline Foz do lguaçù/PR & $\vdots$ \\
\hline Santana do Livramento/RS & $\vdots$ \\
\hline Balneário Pinhal/RS & $\vdots$ \\
\hline Novo Hamburgo/RS & $\vdots$ \\
\hline Agudo/RS & $\vdots$ \\
\hline Porto Alegre/Rs & $\vdots$ \\
\hline Santo Antônio da Patrulha/RS & $\vdots$ \\
\hline
\end{tabular}

(d)

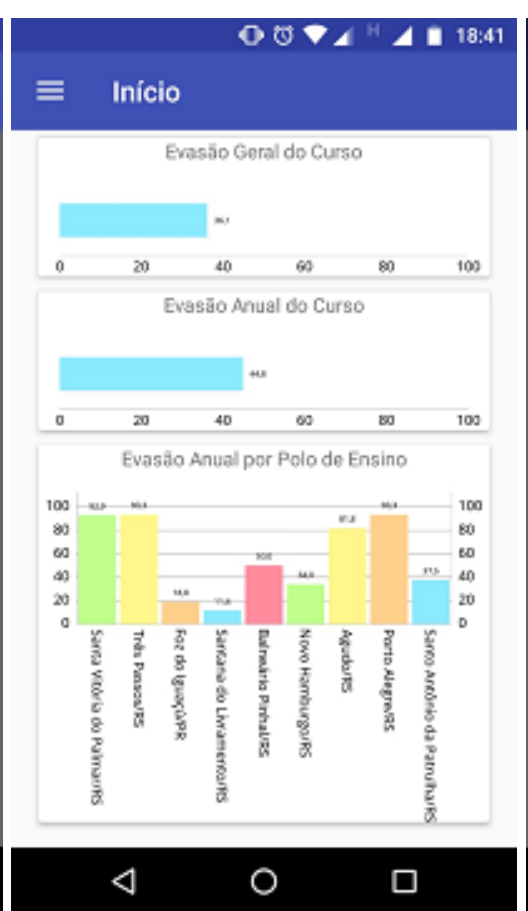

(b)
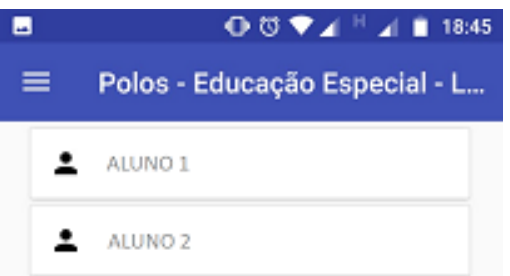

\section{$\triangleleft$}

\section{O}

(e)

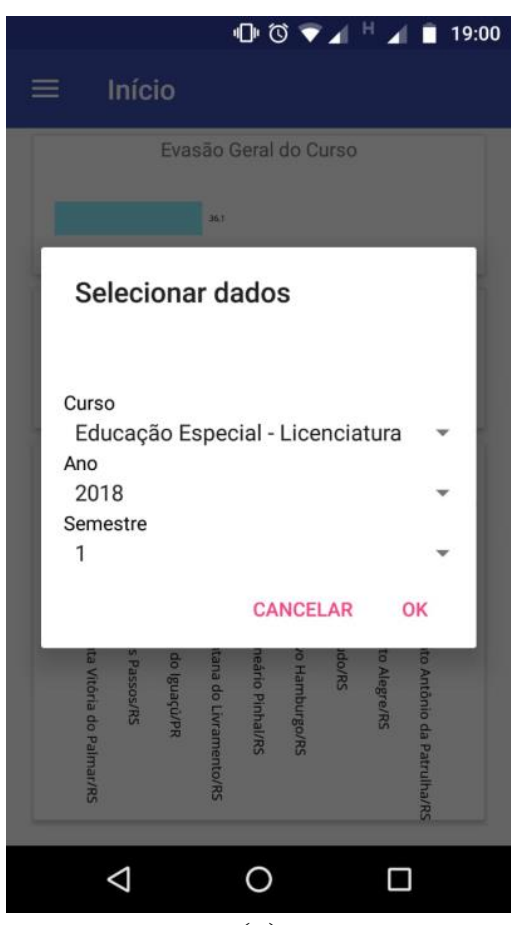

(c)

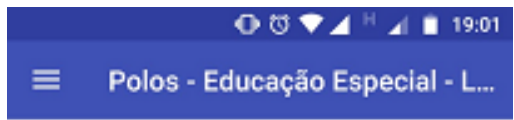

Média de Interap̧öes em Fóruns

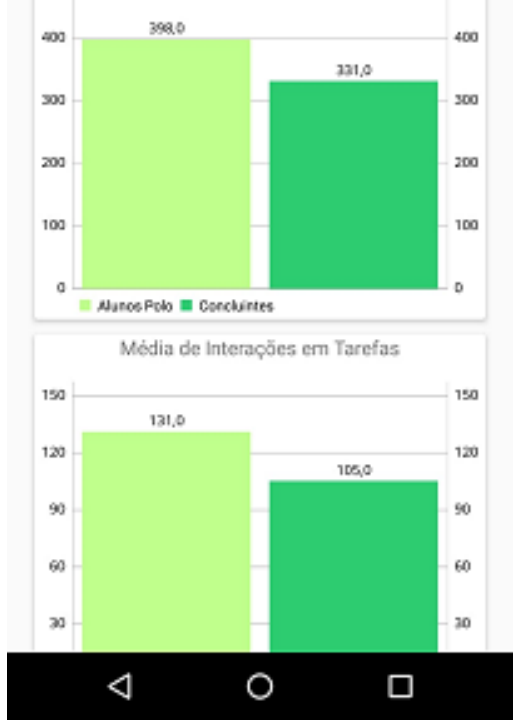

(f)

Figura 2. Funcionalidades do aplicativo

$\mathrm{Na}$ Figura 2(a) é possível visualizar o menu principal. Ele consiste de um menu lateral que possibilita o acesso as demais funcionalidades. Na sequência, a Figura 2(b) exibe os dados do curso em que estão dispostos os indicadores de evasão geral, bem como os indicadores de evasão anual média do curso e dos polos de ensino. Logo em seguida, na Figura 2(c) é possível visualizar a seleção dos dados. Esta tela é composta pelos campos "Curso", "Ano" e "Semestre" sendo nela que se define as informações que serão demonstradas nas demais funcionalidades do aplicativo. A Figura 2(d) demonstra a lista de polos de acordo com um curso selecionado na funcionalidade de 
seleção dos dados. Já a Figura 2(e) exibe a lista de alunos com evasão prevista em um polo selecionado na funcionalidade de listagem de polos.

Por fim, a Figura 2(f) demonstra a funcionalidade de comparação dos dados. Esta funcionalidade pode ser acessada a partir da listagem de polos, Figura 2(d), e da lista de alunos com tendência à evasão, Figura 2(e). A partir da primeira é demonstrada a comparação entre os dados dos alunos do polo de ensino selecionado e os concluintes do curso. Já, a partir da segunda, é demonstrada a comparação entre os dados do aluno selecionado e a média dos alunos concluintes do curso. Os dados demonstrados foram os utilizados no processo de MDE, sendo os dados do AVEA: número de postagens em fóruns, número de visualizações nos fóruns, número de tarefas submetidas, número de visualizações de materiais, número de visualização de links, número de visualizações a diretórios de materiais, número de interações no wiki e número de interações nos questionários. Além dos dados do AVEA também são demonstrados os dados analisados da base de dados institucional, que são: quantidade de cursos de graduação realizados, quantidade de cursos evadidos, número de disciplinas aprovadas e reprovadas no primeiro semestre do curso e número de disciplinas aprovadas e reprovadas no último semestre do curso.

De forma a facilitar o entendimento da relação entre as funcionalidades, na Figura 3 é demonstrado o fluxo de utilização do aplicativo.

Figura 3. Fluxo de utilização da ferramenta iPermanency

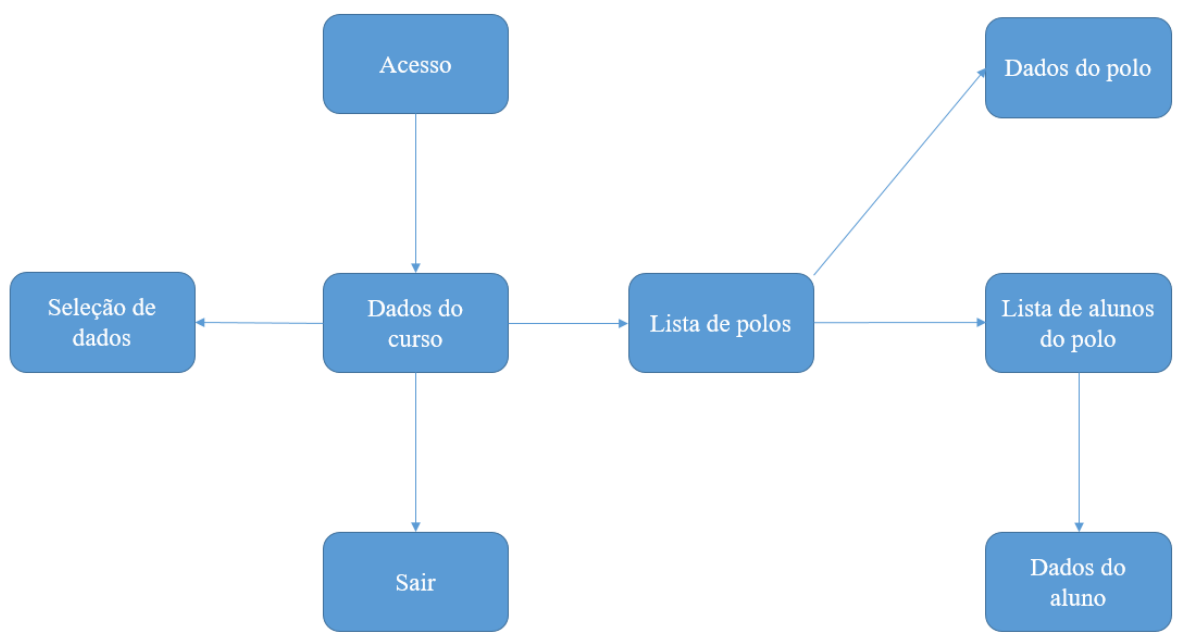

Após a implementação foram realizados os testes com o intuito de assegurar a qualidade do desenvolvimento. Além disso, o aplicativo foi verificado junto aos usuários quanto ao atendimento dos objetivos estabelecidos. Os aspectos relacionados com a avaliação serão abordados na seção cinco.

\section{Avaliação}

Após a concepção do aplicativo procedeu-se com a sua avaliação junto aos coordenadores de cursos de graduação $\mathrm{EaD}$ de uma universidade federal. Para auxiliar neste aspecto foi utilizado o framework DECIDE proposto por Preece, Rogers e Sharp (2013), que estabelece as etapas que orientam o planejamento e a realização da avaliação, conforme descritas nas subseções seguintes.

\subsection{Levantamento dos objetivos e definição das questões}

No contexto da pesquisa, o objetivo principal da avaliação foi verificar junto aos coordenadores de cursos o quanto os dados oriundos do processo de MDE, 
disponibilizados pelo aplicativo, podem auxiliá-los nas atividades de gestão de permanência dos alunos.

Após a definição dos objetivos, devem ser estabelecidas as questões a serem respondidas. Sendo assim, foram relacionadas as seguintes questões:

a) As informações dos alunos com tendência à evasão no semestre são relevantes para a gestão?

b) Dos alunos previstos, já havia conhecimento no seu enquadramento nesta situação?

c) Em relação às informações utilizadas no processo de MD, elas auxiliam na identificação dos fatores que levaram ao apontamento do aluno na previsão?

d) Se a disponibilização destes dados por meio do aplicativo fosse adotado no âmbito institucional, você iria utilizá-lo?

e) Em relação ao aplicativo, achou fácil de usar?

f) Teria alguma sugestão em relação às funcionalidades disponibilizadas?

\subsection{Escolha dos métodos de identificação, questões práticas e éticas}

A avaliação foi realizada individualmente junto a cada coordenador. Em um primeiro momento, o aplicativo foi demonstrado. Após, foi procedida com entrevista abordando as questões definidas. Em relação às questões práticas, o avaliador deveria possuir um dispositivo móvel para demonstração do aplicativo para o participante. Isso foi necessário, pois o aplicativo não foi concedido diretamente para os coordenadores, já que no escopo do desenvolvimento não estavam relacionadas questões de permissão de acesso das informações. Sobre as questões éticas, no convite foi esclarecido o intuito da avaliação. Nele, também foi esclarecido que, caso não deseje, sua identificação não seria indicada na pesquisa.

\subsection{Avaliação, interpretação e apresentação dos resultados}

A avaliação do aplicativo e dos dados foi feita junto a três coordenadores de cursos de graduação EaD. Em um primeiro momento foram expostos os objetivos do trabalho e como eles foram abordados. Em seguida, foram levantadas informações junto a eles que pudessem esclarecer a forma como monitoravam a evasão nos seus cursos. Por fim, o aplicativo foi demonstrado e realizadas as questões da avaliação.

$\mathrm{Na}$ questão "A", relacionada com a importância das informações da evasão para a gestão, os coordenadores foram unânimes em afirmar que os dados disponibilizados são relevantes para assessorar nas suas atividades de gestão. No que tange ao conhecimento do enquadramento dos alunos como prováveis desistentes, questão "B", ambos reconheceram alguns alunos indicados no aplicativo. Além disso, afirmaram que dos alunos reconhecidos alguns haviam abandonado o curso no semestre avaliado e outros ainda estavam matriculados, porém somente para manter vínculo com o curso.

A questão "B" também abordava a forma como os coordenadores obtinham o conhecimento em relação aos alunos. De acordo com suas respostas, a informação era obtida acompanhando o processo de rematrícula dos alunos nos portais da instituição, por meio de relatórios de alunos matriculados e pelo AVEA MOODLE. Boa parte desse conhecimento também é obtido pessoalmente pelos tutores e, posteriormente, repassado aos coordenadores.

Em relação aos dados comparativos, questão "C", disponíveis nas funcionalidades de dados do polo e do aluno, dois coordenadores afirmaram que eles auxiliam na descoberta dos fatores que levaram a indicação do aluno como provável evadido. Ainda, afirmaram que os dados comparativos por polo permitem a descoberta 
dos recursos do AVEA MOODLE que são pouco utilizados pelos alunos em um determinado polo de ensino. Essas informações permitem ao coordenador tomar ações junto aos tutores no sentido de explorar melhor tais recursos.

Nas questões específicas do aplicativo, questões " $D$ " e "E", as respostas foram positivas. Os coordenadores afirmaram que utilizariam a ferramenta, no caso de ser promovida no âmbito institucional, e que acharam a mesma de fácil utilização. Por fim, na questão " $F$ ", em relação a novas funcionalidades, foram sugeridas a possibilidade de análise dos dados por turmas, a visualização dos dados históricos dos índices de evasão e a disponibilização do aplicativo para plataforma IOS.

Com base nas entrevistas foi possível perceber que a evasão é um tema que gera muitas preocupações para os gestores educacionais. No entanto, não existem aparatos projetados para a disponibilização de dados que possam indicar de forma objetiva os alunos com possibilidade de evadirem. Sendo assim, para obter estas informações os coordenadores analisam os dados disponíveis em diversos sistemas de informação. Além disso, é utilizado o conhecimento empírico dos tutores em relação aos alunos. Desse modo, considerando a quantidade de alunos matriculados nos cursos EaD, é inviável por parte da gestão analisar em detalhes os dados dos alunos e, ainda, buscar formas de impedir que a ocorrência da evasão se concretize. Nesse cenário, foi possível constatar que os dados obtidos pela MD são informações estratégicas para os gestores o que, consecutivamente, despertou o interesse de todos pela utilização do aplicativo.

Além da listagem dos alunos, foi destacada pelos coordenadores a importância dos dados relacionados aos indicadores de evasão por polo, disponível na tela principal do aplicativo. Segundo a opinião deles esse indicador permite definir, por exemplo, para quais polos de ensino serão ofertadas novas turmas de acordo com os índices apresentados.

Algumas causas de evasão também foram pontuadas pelos coordenadores, como: a evasão tende a ocorrer nos primeiros semestres do curso, os polos com participação ativa dos tutores apresentam menores índices de desistência, a exigência de um percentual mínimo de aproveitamento pelo aluno para manter vínculo com programas de estágio contribui para manter o aluno no curso e polos próximos a instituição sede tendem a apresentar maiores índices de evasão.

\section{Conclusões e trabalhos futuros}

A evasão é um dos temas de grande relevância para a gestão educacional em todos os níveis de ensino. $\mathrm{Na} \mathrm{EaD}$ o tema é ainda mais preocupante devido algumas habilidades requeridas pelos participantes. Nesse cenário várias abordagens que buscam a identificação de alunos com tendência à evasão empregando técnicas de MDE vêm sendo propostas. No entanto, os conhecimentos obtidos nessas pesquisas não chegam até a gestão educacional.

De forma a aparar esta lacuna a presente pesquisa apresentou o desenvolvimento de um aplicativo móvel para disponibilizar os dados oriundos da aplicação de técnicas de MDE para gestão acadêmica. $\mathrm{O}$ aplicativo desenvolvido foi avaliado junto aos gestores. Nessa avaliação foi possível constatar a importância para a gestão da obtenção dessas informações já que, atualmente, conforme relatado, somente é possível obtê-las de forma manual, analisando diversos relatórios e sistemas de informação. Outro ponto a considerar é que a disposição dessas informações em um único lugar permite ao gestor direcionar os seus esforços na realização de estratégias para evitar o abandono. 
Por fim, informações quantitativas, como índices de evasão por polo de ensino, podem auxiliar nas tomadas de decisões como, por exemplo, na definição dos polos onde serão ofertadas novas turmas.

Como trabalhos futuros sugere-se a extensão da avaliação a um número maior de gestores de forma a consolidar os resultados obtidos na avaliação inicial. Além disso, implementação da gestão de acessos aos dados do aplicativo, bem como a possibilidade de o gestor informar dados sobre ações realizadas para evitar a evasão de forma que as experiências obtidas possam ser "reaproveitadas" por coordenadores de outros cursos ou menos experientes.

\section{Referências}

ABBAD, G. S., ZERBINI, T. e SOUZA, D. B. L. Panorama das pesquisas em educação a distância no brasil. Estudos de Psicologia, Natal, vol.15, n.3, p 291-298. set. 2010.

ABRAHAMSSON, P., HANHINEVA, A., HULKKO, H., IHME, T., JÄÄLINOJA, J., KORKALA, M., KOSKELA, J., KYLLÖNEN, P. SALO, O. Mobile-D: an agile approach for mobile application development. In: ACM SIGPLAN CONFERENCE ON OBJECT-ORIENTED PROGRAMMING SYSTEMS, LANGUAGES, AND APPLICATIONS, 19, 2004 p.174-175.

ASSOCIAÇÃO BRASILEIRA DE EDUCAÇÃO A DISTÂNCIA, ABED. Censo EaD BR 2016: Relatório Analítico da Aprendizagem a Distância no Brasil. 2016. São Paulo.

BIZARRIA, F. P. A., SILVA, M. A. e CARNEIRO, T. C. J. Evasão discente na EaD: percepções do papel do tutor em uma instituição de ensino superior. In: CONGRESSO BRASILEIRO DE ENSINO SUPERIOR A DISTÂNCIA ESUD. 11., 2014. Florianópolis. Anais.

BURGos, C., CAMPANARIO, M. L., PEÑA, D., LARA, J. A., LIZCANO, D. E MARTINEZ, M. A. Data mining for modeling students' performance: A tutoring action plan to prevent academic dropout. Computers \& Electrical Engineering. 2017.

COSTA, S. S., CAZELLA, S., e RIGO, S. J. Minerando dados sobre o desempenho de alunos de cursos de educação permanente em modalidade EAD: Um estudo de caso sobre evasão escolar na UNA-SUS. Revista Novas Tecnologias na Educação, vol.12, n.2. 2014.

DETONI, D., ARAÚJO, R. e CECHINEL, C. Modelling and Prediction of Distance Learning Students Failure by using the Count of Interactions. Revista Brasileira de Informática na Educação, vol.23, 2015, p.1-11.

FERREIRA, V. S. e ELIA, M. F. Uma modelagem conceitual para apoiar a identificação das causas da evasão escolar em EAD. In: WORKSHOP DE INFORMÁTICA NA ESCOLA - WIE. 19, 2013.

KANTORSKI, Z. G., FLORES, E. G., HOFFMANN, I. L., SCHMITT, J. A. e BARBOSA, F. P. Uma Abordagem para Previsão de Evasão em Cursos de Graduação Presenciais. In: SIMPÓSIO BRASILEIRO DE INFORMÁTICA NA EDUCAÇÃO - SBIE. 27, 2016.

KOSTOPOULOS, G., SOTIRIS, K. e PANAGIOTIS, P. Estimating student dropout in distance higher education using semi-supervised techniques. In: PROCEEDINGS 
OF THE 19TH PANHELLENIC CONFERENCE ON INFORMATICS, 2015. p.38-43.

MAIA, C. e MATTAR, J. ABC da EaD: a Educação a Distância hoje. São Paulo: Pearson. 2007. $138 \mathrm{p}$.

MANHÃES, L. M. B. Predição Do Desempenho Acadêmico De Graduandos Utilizando Mineração De Dados Educacionais. Rio de Janeiro: UFRJ, 2015. 157p. Tese de Doutorado.

MARTINS, C. Z., GEBRAN, R. A. e TERÇARIOL, A. A. L. A evasão na perspectiva dos alunos: Uma análise no curso de administração a distância. In: SIMPÓSIO INTERNACIONAL DE EDUCAÇÃO A DISTÂANCIA - SIED. 2. 2014.

NASCIMENTO, R. L. S., DA CRUZ JUNIOR, G. G., e DE ARAÚJO FAGUNDES, R. A. Mineração de Dados Educacionais: Um Estudo Sobre Indicadores da Educação em Bases de Dados do INEP. Revista Novas Tecnologias na Educação, vol.16, n.1. 2018.

PREECE, J., ROGERS, Y. e SHARP, H. Interaction design: beyond human-computer interaction. New York: John Wiley \& Sons. 2013. 656 p.

QUEIROGA, E. M., CECHINEL, C., ARAÚJO, R. M. e BRETANHA, G. C. Generating models to predict at-risk students in technical e-learning courses. In: LEARNING OBJECTS AND TECHNOLOGY - LACLO, LATIN AMERICAN CONFERENCE, 2016. p. 1-8.

REINO, L. R. A. C., HERNÁNDEZ-DOMÍNGUEZ, A., FREITAS JÚNIOR, O. G., CARVALHO, V., BARROS, P. A. M. e BRAGA, M. Análise das Causas da Evasão na Educação a Distância em uma Instituição Federal de Ensino Superior. In: SIMPÓSIO BRASILEIRO DE INFORMÁTICA NA EDUCAÇÃO - SBIE. 26. 2015.

RIGO, S. J. e CAZELLA, S. C. Aplicações de Mineração de Dados Educacionais e Learning Analytics com foco na evasão escolar: oportunidades e desafios. Revista Brasileira de Informática na Educação - RBIE, vol. 22, 2014. p.132-146.

SCHMITT, J.A. Identificação de alunos com tendência à evasão nos cursos de graduação à distância por meio de mineração de dados educacionais. Santa Maria: PPGTER/UFSM, 2018. 175p. Dissertação de Mestrado.

SILBERSCHATZ, A., KORTH, H. F. e SUDARSHAN, S. Sistema de Banco de Dados. Rio de Janeiro: Elsevier, 2012. 791p.

SILVEIRA, C. A. B. Educação a Distância e a Evasão: Estudo de Caso da Realidade no Polo UAB de Franca. In: SIMPÓSIO INTERNACIONAL DE EDUCAÇÃO A DISTÂNCIA. 2012 